\title{
Sektor Unggulan Daerah Kabupaten Buru
}

\author{
Noch Fernando Jelira ${ }^{*}$, M. Faisal Sangadji ${ }^{1}$, Abdullah $^{1}$ \\ 1 Universitas Iqra Buru, Indonesia \\ *Korespondensi: fernandojelirauniabu@gmail.com
}

\begin{tabular}{|c|c|}
\hline Info Artikel & \\
\hline $\begin{array}{l}\text { Diterima } 05 \\
\text { Januari } 2022\end{array}$ & $\begin{array}{l}\text { Penelitian ini mengkaji pembangunan ekonomi daerah melalui sektor } \\
\text { unggulan yang ada pada kabupaten Buru. Pendekatan sektoral } \\
\text { menitikberatkan pada sektor ekonomi sehingga basis ekonomi menjadi } \\
\text { landasan utama dalam proses peningkatan pembangunan daerah di }\end{array}$ \\
\hline Disetujui 04 & kabupaten Buru. Ada empat subjek utama dalam penelitian ini yaitu (1) \\
\hline Februari & $\begin{array}{l}\text { sector unggulan kabupaten Buru dalam kaitannya dengan pertumbuhan } \\
\text { ekonomi daerah (2) analisis basis ekonomi dengan pendekatan Local }\end{array}$ \\
\hline $\begin{array}{l}\text { Dipublikasikan } 11 \\
\text { Februari } 2022\end{array}$ & $\begin{array}{l}\text { Question dan Multiplier, (3) Analisis pertumbuhan ekonomi dengan Shift } \\
\text { Share, dan (4) Analisis strategi kebijakan dalam rangka peningkatan }\end{array}$ \\
\hline $\begin{array}{c}\text { Keywords: } \\
\text { Sektor Unggulan, } \\
\text { Kabupaten Buru, } \\
\text { Pembangunan } \\
\text { Ekonomi Daerah }\end{array}$ & $\begin{array}{l}\text { pengembangan daerah di Kabupaten Buru. Penelitian ini menggunakan } \\
\text { mixed methods dengan pendekatan kuantitif dan kualitatif. Hasil penelitian } \\
\text { menunjukkan ditemukan lima sektor basis ekonomi di Kabupaten Buru dan } \\
\text { tiga belas sector non basis. Selanjutnya ditemukan bahwa Efek Penggada } \\
\text { (multiplier) Pendapatan Sektor Basis Lebih besar dari pada efek penggada } \\
\text { pendapatan di sektor non Basis. }\end{array}$ \\
\hline (C) 2022 The & Abstract \\
\hline $\begin{array}{l}\text { Author(s): This is } \\
\text { an open-access } \\
\text { article distributed } \\
\text { under the terms of } \\
\text { the Creative } \\
\text { Commons } \\
\text { Attribution } \\
\text { ShareAlike (CC BY- } \\
\text { SA 4.0) }\end{array}$ & $\begin{array}{l}\text { This study examines regional economic development through the leading } \\
\text { sectors in Buru district. The sectoral approach focuses on the economic so } \\
\text { that the economic base is fundamental in the process of developing } \\
\text { regional development in Buru district. There are four main subjects } \\
\text { discussed in this study, namely (1) the leading sector of Buru district in } \\
\text { relation to regional economic growth (2) analysis of the economic base } \\
\text { with the Local Question and Multiplier approach, (3) Analysis of economic } \\
\text { growth with Shift Share, and (4) Analysis of policy strategies in the context } \\
\text { of increasing regional development in Buru Regency. This study uses } \\
\text { mixed methods with the approach of quantitative and qualitative methods. }\end{array}$ \\
\hline${ }_{B Y}$ SA & $\begin{array}{l}\text { The results showed that there were five basic economic sectors in Buru } \\
\text { Regency and thirteen non-basic sectors. Furthermore, it is found that the } \\
\text { income multiplier effect in the base sector is greater than the income } \\
\text { multiplier effect in the non-base sector. }\end{array}$ \\
\hline
\end{tabular}

\section{Pendahuluan}

Pembangunan daerah sangat diperlukan dalam upaya mendukung tercapainya percepatan pembangunan nasional. Percepatan dan pemerataan pembangunan akan memberi dampak positif dalam pendayagunaan sumber daya yang tersedia demi tercapainya arus ekonomi yang lebih baik. Oleh sebab itu, pemerintah dan warga memiliki tanggung jawab bersama dalam mendayagunakan 
kemampuan secara maksimal dan terintegrasi (Tri Basuki \& Gayatri, 2009). Usaha ini diperlukan agar pemerataan pembangunan di seluruh pelosok tanah air dapat terwujud. Dengan demikan, daerah yang tertinggal dan terpencil juga akan dapat tumbuh berkembang seperti halnya daerah-daerah yang sudah maju dan modern (Mangilaleng et al., 2015).

Sektor ekonomi yang mempunyai kemampuan tumbuh lebih besar cenderung dibesarkan lebih dini yang setelah itu diiringi oleh pertumbuhan sektor lain yang kurang menguntungkan (Marasabessy et al., 2021). Keseluruhan sektor memang tidak dapat diprioritaskan secara serentak, perlu adanya urgensi dan skala prioritas sehingga pengembangan daerah memang harus dilaksanakan secara bertahap (Armelly et al., 2021). Sektor yang memiliki kapasitas perkembangan yang cepat dapat diprioritaskan terlebih dahulu kemudian diikuti oleh sektor-sektor berikutn ya. Dengan demikian diharapkan dapat memeberikan efek dominan pada percepatan sektor lainnya dan pertu mbu han pembanguan pada u munya.

Keberhasilan pembangunan ekonomi daerah oleh sektor nasional atau swasta untuk meningkatkan kesejahteraan penduduk dapat diukur dengan menggunakan produk domestik bruto (PDRB) daerah (Herman Syahputra, 2015). Produk domestik bruto di daerah merupakan indikator penting keberhasilan pembangunan daerah yang dilakukan dan juga turut menentukan arah pembangunan ke depan (Soeyatno, 2019). Kemudian kebijakan pembangunan ekonomi daerah yang ditetapkan oleh sebuah wilayah harus disesuaikan dengan kondisi (kebutuhan daerah dan potensi daerah) yang bersangkutan (Ma'ruf, Ahmad., 2003). Oleh sebab itu penetian tentang keadaan tiap daerah harus dilakukan agar dapat mengetahui dan menellah informasi pengembangan sebu ah wilayah.

Kabupaten Buru memiliki banyak sumber daya dan lokasi yang strategis sehingga memacu Pemerintah Daerah Kabupaten Buru berkeinginan untuk mengelola dan meningkatkan daerahnya (Sam, Belinda, 2019). Serangkaian agenda dicanangkan Pemerintah Kabupaten Buru dalam rangka percepatan pembangunan wilayah Kabupaten Buru khusunya kawasan yang mempunyai produk ataupun komoditi unggulan dan program- program pendukung lainya (BPS, 2015).

Lewat bermacam kajian penelitian tentang analisis sektor unggulan dan perencanaan secara matang dan profesional, diharapkan pengembangan daerah pada akhirnya berimbas pada kemajuan ekonomi daerah (Sundaro, 2021). Untuk itu pembangunan sektor unggulan wajib dijadikan prioritas utama Pemerintah Daerah Kabupaten Buru guna meningkatkan pengembangan daerah secara maksimal.

Kabupaten Buru mempunyai kemampuan sumberdaya yang jika dimanfaatkan akan memberi hasil dan nilai ekonomi yang tinggi. Selama ini sumber daya tersebut belum dimanfaatkan secara maksimal. Dengan demikian, kebijakan pembangunan terhadap sektor unggulan daerah harus digaungkan agar permasalahan pembangunan dapat menemukan solusinya.

Berbagai kekurangan dan kelebihan, mendesak Pemerintah Daerah Kabupaten Buru memanfaatkan dan memaksimalkan sumberdaya yang ada, sehingga program pembangunan yang sepanjang ini dicita- citakan bisa berjalan sesuai dengan perencanaan untuk mewujudkan kesejahteraan warga. 
Adapun permasalahan penelitian meliputi:

a. Sektor unggulan apa saja dari Kabupaten Buru yang dapat dimunculkan sebagai sektor prioritas dalam pembangunan daerah.

b. Bagaimana akibat pengganda (Multiplier) pendapatan sektor unggulan Kabupaten Buru.

c. Sejauh mana peran dari sektor unggulan berdampak pada tingkat pertumbuhan ekonomi daerah Kabupaten Buru

d. Bagaimana strategi kebijakan yang tepat untuk membangun Kabupaten Buru yang berbasis pada sektor unggulan daerah (https://burukab.bps.go.id/, 2019).

Penelitian untuk mengkaji pembangunan wilayah berdasarkan sektor utama Kabupaten Buru hanya terfokus pada pendekatan sektoral. Pendekatan sektoral menitikberatkan pada sektor ekonomi. Pendekatan sektoral yang merangkum dan menganalisis semua kegiatan ekonomi di dalam kawasan yang direncanakan.

\section{Metode}

Penelitian dilakukan di Kabupaten Buru. Penelitian ini diawali pada bulan Mei hingga Juli 2019. Pemilihan wilayah diagendakan secara terencana berdasarkan pertimbangan dari hasil kajian yang sudah dilakukan. Pertimbangan awal Kabupaten Buru ialah wilayah yang sangat potensial buat dibesarkan, kedua penelitian unggulan masih jadi kajian strategis Pemerintah Wilayah Kabupaten Buru. Informasi yang disampaikan dalam analisis ini merupakan informasi primer serta informasi sekunder (Lismuba Indriani dan Mohammad Abdul Mukhyi, 2013). Informasi primer diperoleh lewat hasil wawancara dengan informan dari lembaga terpaut selaku aksesoris informasi sekunder. Sebaliknya informasi sekunder dikumpulkan dari bermacam sumber antara lain Kantor Bappeda, BPS Kabupaten Buru, BPS Propinsi Maluku serta lembaga ataupun lembaga lain di Kabupaten Buru. Informasi yang diperlukan dari informasi sekunder ialah informasi time series tahun 2015-2019. Informasi sekunder ini berikutnya diolah dengan memakai program Microsoft Excel serta SPSS 17. 0.

Penelitian ini berfokus pada tingkat kabupaten (tercantum kecamatan) dengan tujuan untuk mencerminkan studi ekonomi utama dalam memprioritaskan pembangunan daerah. Mixed method analisis dari Croswell digunakan dalam kajian ini (Sugiyono, 2011).

Tabel 1. Metode Analisis yang digunakan.

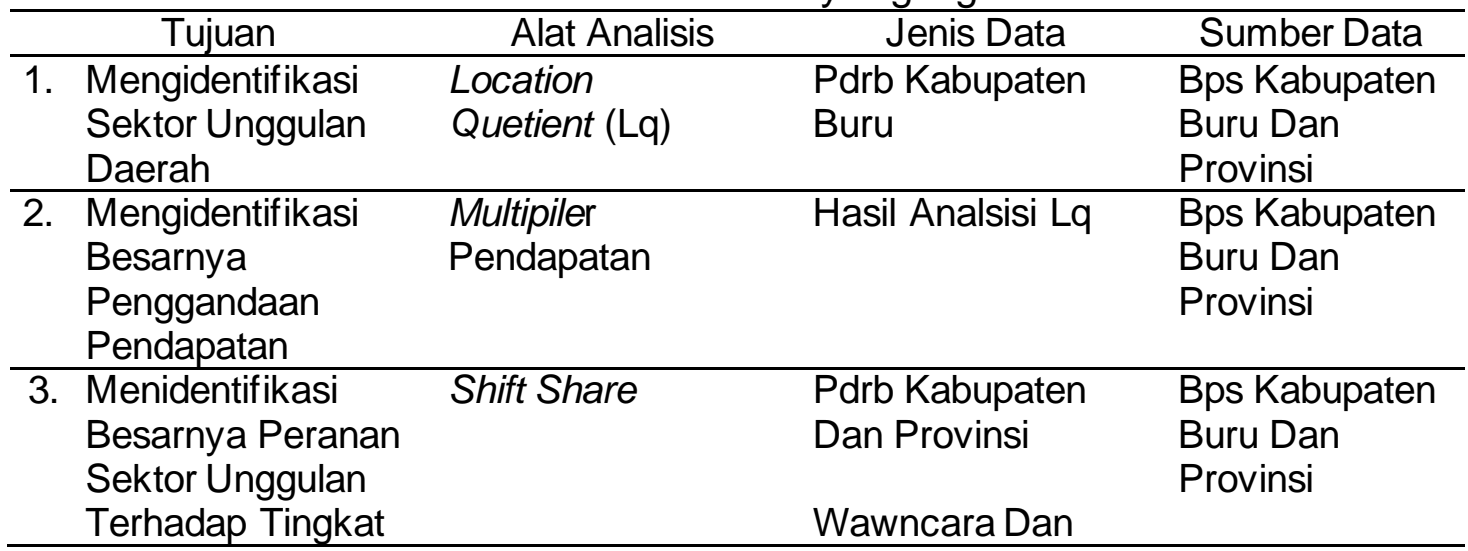




\begin{tabular}{lll}
\hline Pertumbuhan & Masyakat Dan & Bapedda Dan \\
Ekonomi & Pemerintah & Dinas-Dinas \\
& Kabupaten & Terkait Di \\
& & Kabupaten \\
\hline
\end{tabular}

Berdasarkan tabel 1 di atas, Location Quotient (LQ) dapat digunakan untuk menganalisis data guna menentukan sector unggulan daerah. Hasil tersebut kemudian dapat digunakan untuk menghitung besarnya efek pengganda pendapatan. Sebaliknya penentuan besaran nilai sector unggulan dalam implikasinya terhadap pertumbuhan ekonomi diukur melalui Shift Share.

Data dalam penelitian ini diambil dari PDRB kabupaten dan propinsi. Adapun data kualitatif diperoleh dari hasil wawancara dengan informan atau sumber di instansi pemerintah daerah masing-masing.

\section{Hasil dan Pembahasan}

\subsection{Analisis Location Quotient (LQ)}

Dalam rangka menentukan nilai $L Q$ suatu sektor terlebih dahulu perlu dikalkulasi rasio persen relatif PDRB Kabupaten Buru berdasarkan Harga Konstan 2010 menurut lapangan usaha terhadap PDRB Provinsi Maluku dari Dasar Harga Konstan 2010 berdasarkan lapangan usaha menggunakan data series tahun 2015 s/d 2019

Tabel 2. Persentase Relatif PDRB ADHK 2010 Menurut Lapangan Usaha di Kabupaten Buru Tahun 2015-2019.

\begin{tabular}{|l|r|r|r|r|r|r|}
\hline \multirow{2}{*}{ Lapangan Usaha } & \multicolumn{5}{|c|}{ Persen Relatif PDRB Kabupaten Buru ADHK 2010} \\
\cline { 2 - 7 } & \multicolumn{1}{|c|}{2015} & \multicolumn{1}{c|}{2016} & \multicolumn{1}{c|}{2017} & \multicolumn{1}{c|}{$\mathbf{2 0 1 8}$} & \multicolumn{1}{c|}{$\mathbf{2 0 1 9}$} & Rata-rata \\
\hline Pertanian, Kehutanan, dan Perikanan & 33.84 & 33.92 & 34.12 & 33.99 & 33.78 & 33.93 \\
\hline Pertambangan dan Penggalian & 0.72 & 0.70 & 0.68 & 0.67 & 0.67 & 0.69 \\
\hline Industri Pengolahan & 12.78 & 12.63 & 12.89 & 13.13 & 13.20 & 12.92 \\
\hline Pengadaan Listrik, Gas & 0.10 & 0.10 & 0.09 & 0.09 & 0.09 & 0.09 \\
\hline Pengadaan Air, Pengelolaan Sampah, Limbah dan Daur Ulan & 0.44 & 0.43 & 0.43 & 0.42 & 0.42 & 0.43 \\
\hline Konstruksi & 6.74 & 6.66 & 6.56 & 6.49 & 6.62 & 6.61 \\
\hline Perdagangan Besar dan Eceran, dan Reparasi Mobil dan Ser & 3.33 & 3.32 & 3.28 & 3.34 & 3.30 & 3.31 \\
\hline Transportasi dan Pergudangan & 7.44 & 7.40 & 7.47 & 7.53 & 7.58 & 7.49 \\
\hline Peny ediaan Akomodasi dan Makan Minum & 1.30 & 1.28 & 1.26 & 1.24 & 1.23 & 1.26 \\
\hline Informasi dan Komunikasi & 1.43 & 1.42 & 1.41 & 1.39 & 1.37 & 1.40 \\
\hline Jasa Keuangan & 1.92 & 1.96 & 1.89 & 1.90 & 1.86 & 1.91 \\
\hline Real Estate & 0.46 & 0.44 & 0.43 & 0.41 & 0.39 & 0.43 \\
\hline Jasa Perusahaan & 0.12 & 0.12 & 0.12 & 0.12 & 0.11 & 0.12 \\
\hline Administrasi Pemerintahan, Pertahanan dan Jaminan Sosial & 19.73 & 19.98 & 19.89 & 19.86 & 19.98 & 19.89 \\
\hline Jasa Pendidikan & 4.35 & 4.40 & 4.37 & 4.34 & 4.33 & 4.36 \\
\hline Jasa Kesehatan dan Kegiatan Sosial & 3.61 & 3.56 & 3.50 & 3.47 & 3.48 & 3.52 \\
\hline Jasa lainnya & 1.69 & 1.66 & 1.63 & 1.60 & 1.61 & 1.64 \\
\hline TOTAL PDRB & 100.00 & 100.00 & 100.00 & 100.00 & 100.00 & 100.00 \\
\hline
\end{tabular}

Sumber: burkab.go.id (Data ini didapatkan dari hasil DPR kabuapaten Buru pada tahun 2019) 
Langkah berikutnya adalah perhitungan rasio PDRB Relatif berdasarkan PDRB Provinsi Maluku Atas Dasar Harga Konstan 2010 yang didasrkan pada lapangan usaha, dengan menggunakan data series tahun 2015 s/d 2019

Tabel 3. Persentase Relatif PDRB Atas Dasar Harga Konstan 2010 Menurut Lapangan Usaha di Provinsi Maluku Tahun 2015-2019

\begin{tabular}{|c|c|c|c|c|c|c|}
\hline \multirow{2}{*}{ Lapangan Usaha } & \multicolumn{6}{|c|}{ Persen Relatif PDRB Provinsi Maluku ADHK 2010} \\
\hline & 2015 & 2016 & 2017 & 2018 & 2019 & Rata-rata \\
\hline Pertanian, Kehutanan, dan Perikanan & 23.77 & 23.54 & 23.58 & 23.28 & 23.33 & 23.50 \\
\hline Pertambangan dan Penggalian & 3.26 & 3.21 & 3.04 & 2.66 & 2.43 & 2.92 \\
\hline Industri Pengolahan & 5.38 & 5.44 & 5.39 & 5.46 & 5.31 & 5.39 \\
\hline Pengadaan Listrik, Gas & 0.11 & 0.11 & 0.10 & 0.10 & 0.10 & 0.10 \\
\hline Pengadaan Air, Pengelolaan Sampah, Limbah dan Daur Ulan & 0.48 & 0.47 & 0.47 & 0.46 & 0.46 & 0.47 \\
\hline Konstruksi & 6.89 & 6.84 & 6.83 & 6.96 & 7.09 & 6.92 \\
\hline Perdagangan Besar dan Eceran, dan Reparasi Mobil dan Sep & 14.34 & 14.37 & 14.81 & 14.85 & 15.08 & 14.69 \\
\hline Transportasi dan Pergudangan & 5.48 & 5.39 & 5.29 & 5.29 & 5.27 & 5.34 \\
\hline Peny ediaan Akomodasi dan Makan Minum & 1.84 & 1.73 & 1.71 & 1.69 & 1.69 & 1.73 \\
\hline Informasi dan Komunikasi & 3.95 & 4.03 & 4.04 & 4.01 & 3.94 & 3.99 \\
\hline Jasa Keuangan dan Asuransi & 3.72 & 3.84 & 3.79 & 3.83 & 3.83 & 3.80 \\
\hline Real Estate & 0.35 & 0.34 & 0.33 & 0.32 & 0.31 & 0.33 \\
\hline Jasa Perusahaan & 1.04 & 1.01 & 1.00 & 0.99 & 0.99 & 1.01 \\
\hline Administrasi Pemerintahan, Pertahanan dan Jaminan Sosial & 19.99 & 20.16 & 20.17 & 20.61 & 20.63 & 20.31 \\
\hline Jasa Pendidikan & 5.52 & 5.64 & 5.63 & 5.66 & 5.72 & 5.63 \\
\hline Jasa Kesehatan dan Kegiatan Sosial & 2.18 & 2.18 & 2.15 & 2.14 & 2.15 & 2.16 \\
\hline Jasa lainny a & 1.71 & 1.71 & 1.68 & 1.69 & 1.69 & 1.70 \\
\hline TOTAL PDRB & 100.00 & 100.00 & 100.00 & 100.00 & 100.00 & 100.00 \\
\hline
\end{tabular}

Berdasarkan perbandingan persen relatif PDRB ADHK Kabupaten Bu ru dan Provinsi Maluku diperoleh 5 (lima) kategori sektor basis di Kabupaten Buru yang memiliki keunggulan komparatif (Nilai LQ-nya>1), diantaranya:
a. Industri Pengolahan (LQ sebesar 2,40)
b. Jasa Kesehatan dan Kegiatan Sosial (LQ sebesar 1,63)
c. Pertanian, Kehutanan dan Perikanan (LQ sebesar 1,44)
d. Transportasi dan Pergudangan (LQ sebesar 1,40)
e. Real Estate (LQ sebesar 1,30)

Berikut urutan nilai Location Quotient di Kabupaten Buru berdasarkan PDRB ADHK 2010 Menurut Lapangan Usaha Periode Tahun 2015-2019. 


\section{Perhitungan LQ Rata-rata Kabupaten Buru Tahun 2015-2019}

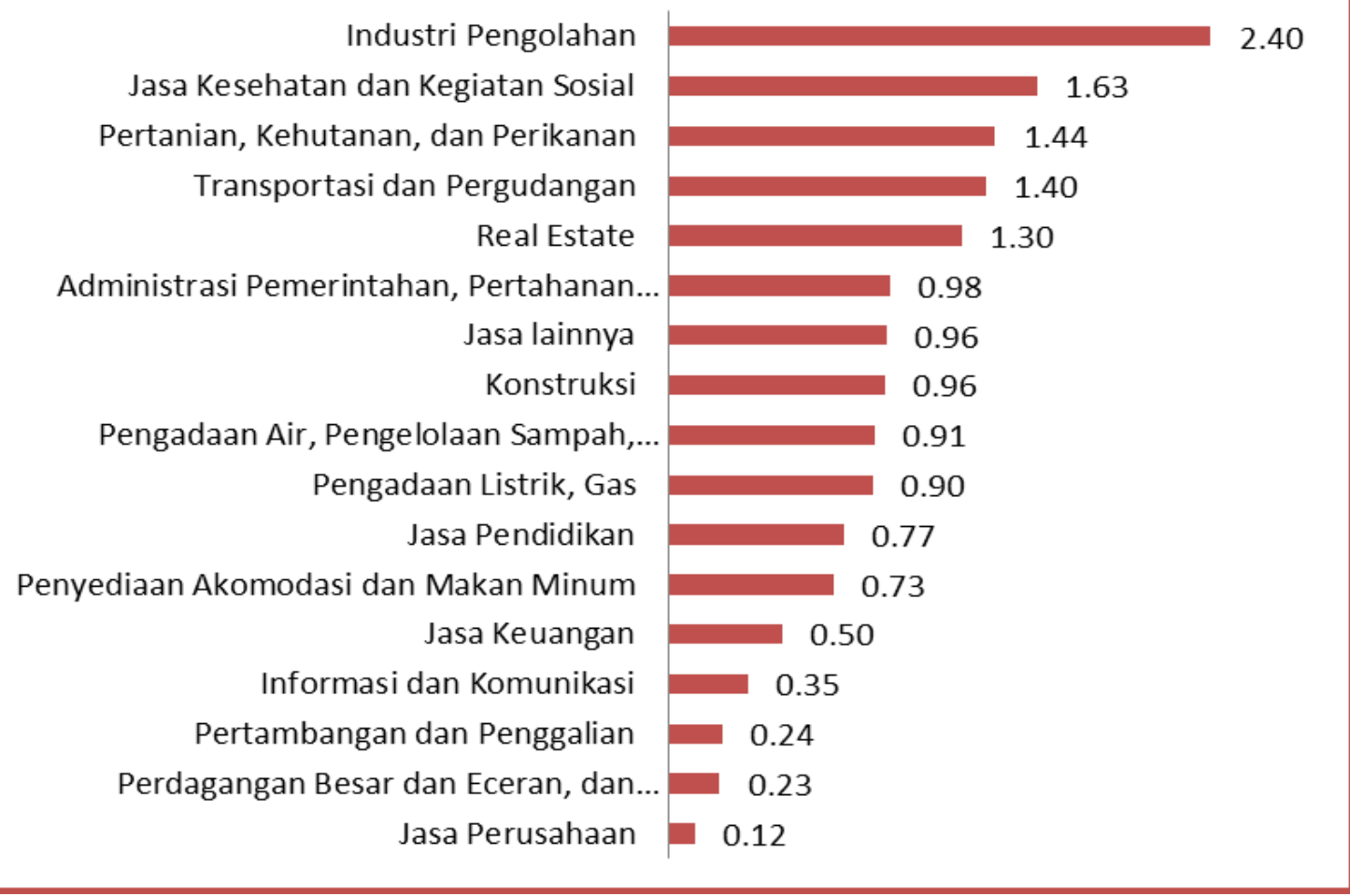

Gambar 1. Perhitungan LQRata-rata Kabupaten Buru Tahun 2015-2019

Keunggulan komparatif pada penelitian basis jenis industri pengolahan hadapi penyusutan pada tahun 2016 berikutnya hadapi kenaikan. Pada jen is jasa kesehatan serta aktivitas sosial cenderung hadapi penyusutan semenjak tahun 2016 hingga tahun 2019, tetapi bersamaan mewabahnya penyakit covid- 19 hingga dengan dikala ini belum ada informasi terpaut jenis tersebut, apakah hadapi kenaikan ataukah malah penyusutan. Pada jenis pertanian, kehutanan serta perikanan ada kecenderungan penyusutan pada tahun 2018 serta 2019, sebaliknya pada ketegori transportasi serta pergudangan cuma hadapi penyusutan pada tahun 2016 berikutnya hadapi tren penimgkatan, kebalikannya jenis real estate hadapi tren penyusutan semenjak tahun 2016 hingga tahun 2019.

Tidak hanya penelitian basis ada pula 12 (dua belas) penelitian non basis selaku penelitian penunjang, penelitian non basis yang bisa diasumsikan selaku penelitian yang belum mandiri serta butuh kenaikan keahlian kapasitas usaha sebab kurang penuhi kebutuhan di wilayah Kabupaten Buru.

\subsection{Analisis Efek Pengganda (Multiplier)}

Nilai besaran multiplier effect berpengaruh pada pertumbuhan ekonomi daerah. Grafik pengurangan belanja diperoleh melalui penjualan barang dan jasa yang dihasilkan oleh daerah, sehingga menentukan pertu mbuhan ekonomi daerah. Dengan demikian gaji atau pendapatan dan pertumbuhan tenaga kerja dapat diidentifikasi dari pengganda ekonomi basis. Total pendapatan daerah tersebut dihiitung dari peggandaan (multifikasi) dari proses perdagangan dan jual beli suatu daerah terhadap pemsaran keluar (expor) barang jasa tersebut keluar daerah. 
Tabel 4. Efek Pengganda (Multiplier) Pendapatan pada Sektor Basis di Kabupaten Buru Tahun 2015-2019.

\begin{tabular}{clcl}
\hline \multirow{2}{*}{ TAHUN } & \multicolumn{2}{c}{ Pendapatan (Milyar Rupiah ) } & Multiplier Sektor \\
\cline { 2 - 3 } & $\begin{array}{c}\text { Pendapatan } \\
\text { Sektor Basisi }\end{array}$ & $\begin{array}{c}\text { Total } \\
\text { Pendapatan }\end{array}$ & \\
\hline 2015 & 669.36 & 1.239 .10 & 1.8512 \\
\hline 2016 & 705.67 & 1.310 .00 & 1.8564 \\
\hline 2017 & 752.83 & 1.388 .73 & 1.8447 \\
\hline 2018 & 801.58 & 1.475 .07 & 1.8402 \\
\hline 2019 & 847.07 & 1.564 .43 & 1.8469 \\
\hline
\end{tabular}

Dari table ini kita bisa melihat bahwa multiplier yang didapatkan dari sektor basis bernilai lebih besar dari sektor non basis dalam kurun waktu dari tahun 20152019. Ada peningkatan sebesar 1,8512 pada tahun 2016 kemudian terjadi penurunan di tahun-tahun setelahnya.

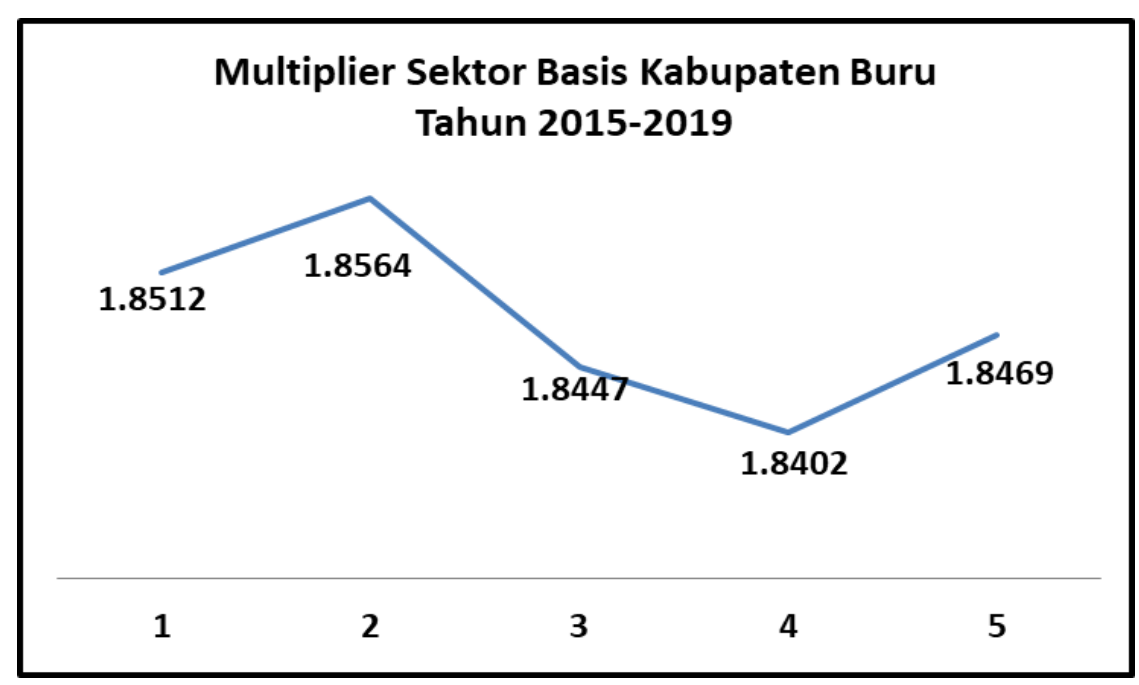

Gambar 2. Multipler Sektor Basis Kabupaten Buru, Tahun 2015-2019. (BPS, 2015)

\section{Analisis Shift Share}

Tingkat pertumbuhan ekonomi di Kabupaten Buru dapat dihitung lewat analisis Shift Share. Mengingat peranannya yang sangat penting, maka Shift Share seringkali digunakan untuk mengidentifikasi pertumbuhan sektor ekonomi selang periode tertentu.

\section{a. Perubahan PDRB}

Unsur utama Shift Share adalah Perubahan indikator kegiatan ekonomi (PDRB) yang biasanya ada dalam setiap sektor lapangan usaha. Dalam tebel 2.1 tersebut PDRB Kabupaten Buru adalah sebesar 26,26 \% dan propinsi Maluku sebesar $25,14 \%$. 
Tabel 5. Perubahan PDRB

\begin{tabular}{|c|c|c|c|c|c|c|c|c|}
\hline \multirow[t]{2}{*}{ Lapangan Usaha } & \multicolumn{4}{|c|}{$\begin{array}{l}\text { PDRB Kabupaten Buru ADHK } 2010 \\
\text { (Milyar Rupiah) }\end{array}$} & \multicolumn{4}{|c|}{$\begin{array}{l}\text { PDRB Provinsi Maluku ADHK } 2010 \text { (MHlyar } \\
\text { Rupiah) }\end{array}$} \\
\hline & 2015 & 2019 & erubahan & $(\%)$ & 2015 & 2019 & erubahan & $(\%)$ \\
\hline Pertanian, Kehutanan, dan Perikanan & 419.35 & 528.39 & 109.04 & 26.00 & $5,908.36$ & $7,256.23$ & $1,347.87$ & 22.81 \\
\hline Pertambangan dan Penggalian & 8.94 & 10.41 & 1.47 & 16.44 & 811.27 & 754.98 & $(56.29)$ & (6.94) \\
\hline Industri Pengolahan & 158.37 & 206.45 & 48.08 & 30.36 & $1,336.32$ & $1,650.66$ & 314.34 & 23.52 \\
\hline Pengadaan Listrik, Gas & 1.21 & 1.36 & 0.15 & 12.40 & 26.99 & 30.23 & 3.24 & 12.00 \\
\hline Pengadaan Air, Pengelolaan Sampah, Limbah dan Daur Ulang & 5.44 & 6.53 & 1.09 & 20.04 & 119.48 & 142.01 & 22.53 & 18.86 \\
\hline Konstruksi & 83.46 & 103.51 & 20.05 & 24.02 & $1,712.13$ & $2,204.85$ & 492.72 & 28.78 \\
\hline Perdagangan Besar dan Eceran, dan Reparasi Mobil dan Sepeda Motor & 92.23 & 118.58 & 26.35 & 28.57 & $3,564.80$ & $4,692.08$ & $1,127.28$ & 31.62 \\
\hline Transportasi dan Pergudangan & 41.30 & 51.70 & 10.40 & 25.18 & $1,361.61$ & $1,639.97$ & 278.36 & 20.44 \\
\hline Penyediaan Akomodasi dan Makan Minum & 16.07 & 19.27 & 3.20 & 19.91 & 456.30 & 526.08 & 69.78 & 15.29 \\
\hline Informasi dan Komunikasi & 17.72 & 21.37 & 3.65 & 20.60 & 981.13 & $1,225.78$ & 244.65 & 24.94 \\
\hline Jasa Keuangan & 23.84 & 29.14 & 5.30 & 22.23 & 924.51 & $1,192.11$ & 267.60 & 28.95 \\
\hline Real Estate & 5.65 & 6.15 & 0.50 & 8.85 & 87.09 & 94.91 & 7.82 & 8.98 \\
\hline Jasa Perusahaan & 1.51 & 1.78 & 0.27 & 17.88 & 258.71 & 307.77 & 49.06 & 18.96 \\
\hline Administrasi Pemerintahan, Pertahanan dan Jaminan Sosial Wajib & 244.53 & 312.53 & 68.00 & 27.81 & $4,969.72$ & $6,418.98$ & $1,449.26$ & 29.16 \\
\hline Jasa Pendidikan & 53.86 & 67.70 & 13.84 & 25.70 & $1,372.33$ & $1,778.00$ & 405.67 & 29.56 \\
\hline Jasa Kesehatan dan Kegiatan Sosial & 44.69 & 54.38 & 9.69 & 21.68 & 542.49 & 668.09 & 125.60 & 23.15 \\
\hline Jasa lainnya & 20.93 & 25.18 & 4.25 & 20.31 & 425.97 & 526.05 & 100.08 & 23.49 \\
\hline TOTAL PDRB & $1,239.10$ & $1,564.43$ & 325.33 & 26.26 & $24,859.21$ & $31,108.78$ & $6,249.57$ & 25.14 \\
\hline
\end{tabular}

Perubahan produksi atau kesempatan kerja tertinggi di Kabupaten Buru ada pada sektor industri pengolahan sebesar $30,36 \%$, perdagangan besar dan eceran dan reparasi mobil dan sepeda motor sebesar $28,57 \%$, administrasi pertanahan dan jaminan sosial wajib sebesar $27,81 \%$, pertanian, kehutanan dan perikanan sebesar $26,00 \%$, jasa pendidikan sebesar $25,70 \%$, jasa kesehatan dan kegiatan sosial sebesar $21,68 \%$, informasi dan komunikasi sebesar $20,60 \%$, jasa lainnya sebesar $20,31 \%$, pengadaan air, pengelolaan sampah, limbah dan daur ulang sebesar $20,04 \%$, penyediaan akomodasi dan makan minum sebesar $19,91 \%$, jasa perusahaan sebesar $17,88 \%$, pertambangan dan penggalian sebesar $16,44 \%$, pengadaan listrik dan gas sebesar $12,40 \%$, dan real estate sebesar $8,85 \%$.

Perubahan produksi atau kesempatan kerja tertinggi di Provinsi Maluku terdapat pada sektor perdagangan besar dan eceran dan reparasi mobil dan sepeda motor sebesar $31,62 \%$, jasa pendidikan sebesar $29,56 \%$, administrasi pertanahan dan jaminan sosial wajib sebesar $29,16 \%$, jasa keuangan sebesar $28,95 \%$, konstruksi sebesar $28,78 \%$, informasi dan komunikasi sebesar $24,94 \%$, industri pengolahan sebesar $23,52 \%$, jasa lainnya sebesar $23,49 \%$. jasa kesehatan dan kegiatan sosial sebesar $23,15 \%$, pertanian, kehutanan dan perikanan sebesar $22,81 \%$, transportasi dan pergudangan sebesar $20,44 \%$, jasa perusahaan sebesar $18,96 \%$, pengadaan air, pengelolaan sampah, limbah dan daur ulang sebesar 18,86\%, penyediaan akomodasi dan makan minum sebesar $15,29 \%$, pengadaan listrik dan gas sebesar $12,00 \%$, real estate sebesar $8,98 \%$, dan pertambangan dan penggalian sebesar $-6,94 \%$, 


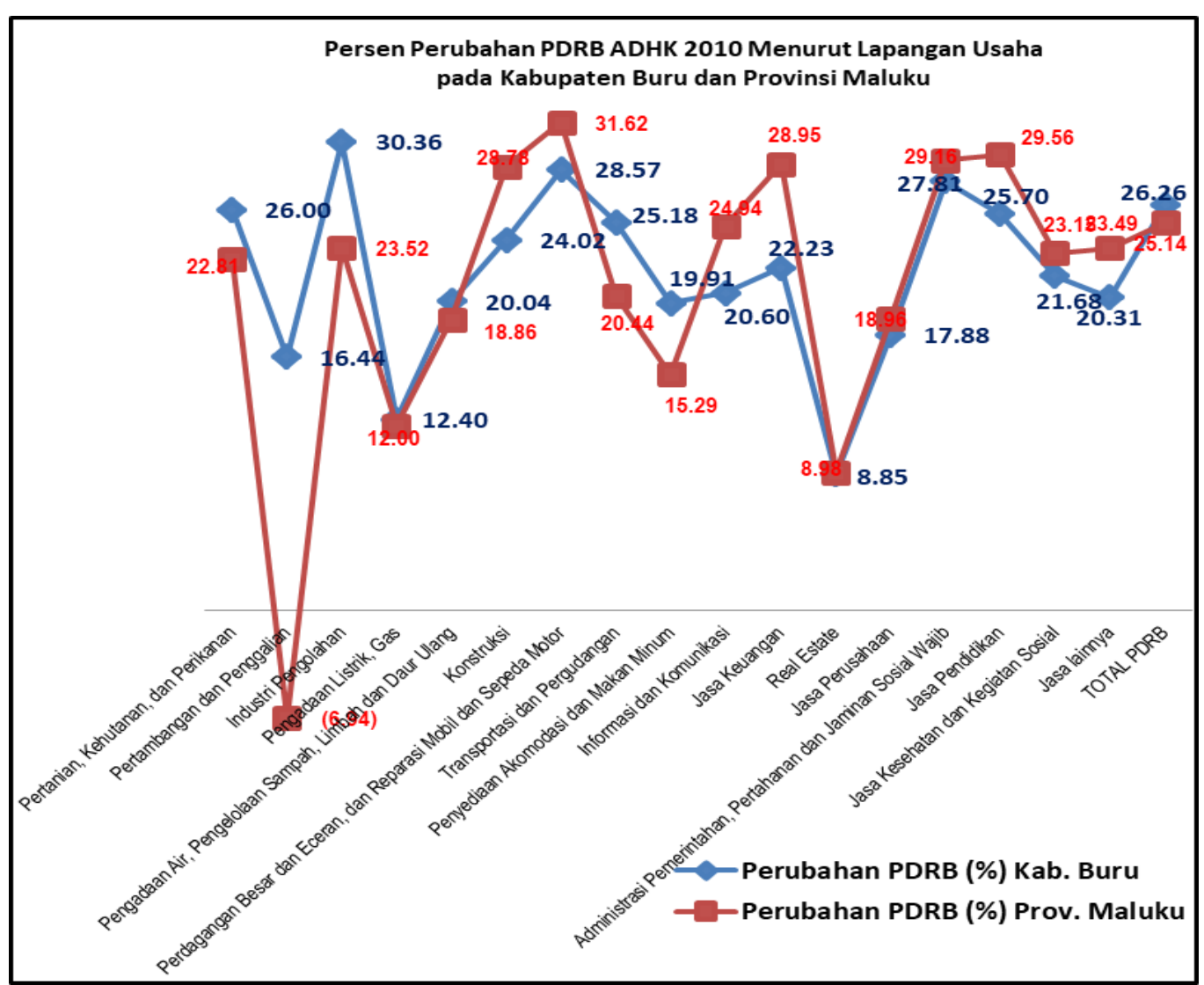

Gambar 3. Grafik perubahan PDRB

\section{b. Komponen Pertumbuhan Daerah}

Komponen pertumbuhan daerah terdiri atas komponen pertumbuhan Propinsi (KPP), komponen pertumbuhan proposional (PP) dan komponen pertumbuhan pangsa daerah (PPW).

Tabel 7. Komponen Pertumbuhan Daerah di Kabupaten Buru.

\begin{tabular}{|c|c|c|c|c|c|c|}
\hline \multirow{2}{*}{ Lapangan Usaha } & \multicolumn{2}{|c|}{ KP Provinsi } & \multicolumn{2}{|c|}{ KP Proporsional } & \multicolumn{2}{|c|}{ KP Pangsa Wilayah } \\
\hline & $\mathrm{Ra}^{*}{ }^{*} \mathrm{Yij}$ & $\%$ & $(\mathrm{Ri}-\mathrm{Ra})^{*} \mathrm{Yij}$ & $\%$ & $(\mathbf{r i - R i})^{*} Y i j$ & $\%$ \\
\hline Pertanian, Kehutanan, dan Perikanan & 105.42 & 25.14 & (9.76) & (2.33) & 13.37 & 3.19 \\
\hline Pertambangan dan Penggalian & 2.25 & 25.14 & (2.87) & $(32.08)$ & 2.09 & 23.38 \\
\hline Industri Pengolahan & 39.81 & 25.14 & $(2.56)$ & $(1.62)$ & 10.83 & 6.84 \\
\hline Pengadaan Listrik, Gas & 0.30 & 25.14 & $(0.16)$ & (13.14) & 0.00 & 0.39 \\
\hline Pengadaan Air, Pengelolaan Sampah, Limbah dan Daur Ulang & 1.37 & 25.14 & $(0.34)$ & $(6.28)$ & 0.06 & 1.18 \\
\hline Konstruksi & 20.98 & 25.14 & 3.04 & 3.64 & (3.97) & $(4.75)$ \\
\hline Perdagangan Besar dan Eceran, dan Reparasi Mobil dan Sepeda Motor & 23.19 & 25.14 & 5.98 & 6.48 & $(2.82)$ & $(3.05)$ \\
\hline Transportasi dan Pergudangan & 10.38 & 25.14 & $(1.94)$ & $(4.70)$ & 1.96 & 4.74 \\
\hline Penyediaan Akomodasi dan Makan Minum & 4.04 & 25.14 & $(1.58)$ & $(9.85)$ & 0.74 & 4.62 \\
\hline Informasi dan Komunikasi & 4.45 & 25.14 & $(0.04)$ & $(0.20)$ & $(0.77)$ & $(4.34)$ \\
\hline Jasa Keuangan dan Asuransi & 5.99 & 25.14 & 0.91 & 3.81 & $(1.60)$ & (6.71) \\
\hline Real Estate & 1.42 & 25.14 & $(0.91)$ & $(16.16)$ & $(0.01)$ & $(0.13)$ \\
\hline Jasa Perusahaan & 0.38 & 25.14 & $(0.09)$ & (6.18) & $(0.02)$ & $(1.08)$ \\
\hline Administrasi Pemerintahan, Pertahanan dan Jaminan Sosial Wajib & 61.47 & 25.14 & 9.83 & 4.02 & (3.31) & $(1.35)$ \\
\hline Jasa Pendidikan & 13.54 & 25.14 & 2.38 & 4.42 & (2.08) & (3.86) \\
\hline Jasa Kesehatan dan Kegiatan Sosial & 11.24 & 25.14 & $(0.89)$ & $(1.99)$ & $(0.66)$ & $(1.47)$ \\
\hline Jasa lainnya & 5.26 & 25.14 & $(0.34)$ & $(1.65)$ & (0.67) & $(3.19)$ \\
\hline
\end{tabular}


Komponen pertumbuhan Propinsi (KPP) sebesar 0,25 atau Rp. 311,51 milyar dan memberikan pengaruh yang sangat penting dalam pertumbuhan ekonomi di Kabupaten Buru. Secara sektoral kontribusi terbesar penyumbang pertumbuhan ekonomi terdapat pada sektor Pertanian, Kehutanan dan Perikanan yaitu sebesar Rp. 105,42 milyar sedangkan nilai KPP terkecil terdapat pada sektor pengadaan listrik dan gas yaitu sebesar Rp. 300 juta.

Tingkat pertumbuhan ekonomi di Kabupaten Buru sangat dipengaruhi oleh kebijakan di tingkat regional, artinya bila terjadi perubahan kebijakan pada sektor perekonomian maka komponen pertumbuhan akan terkoreksi secara riil yang mempengaruhi kontribusi sektor perekonomian terhadap pendapatan PDRB Kabupaten Buru.

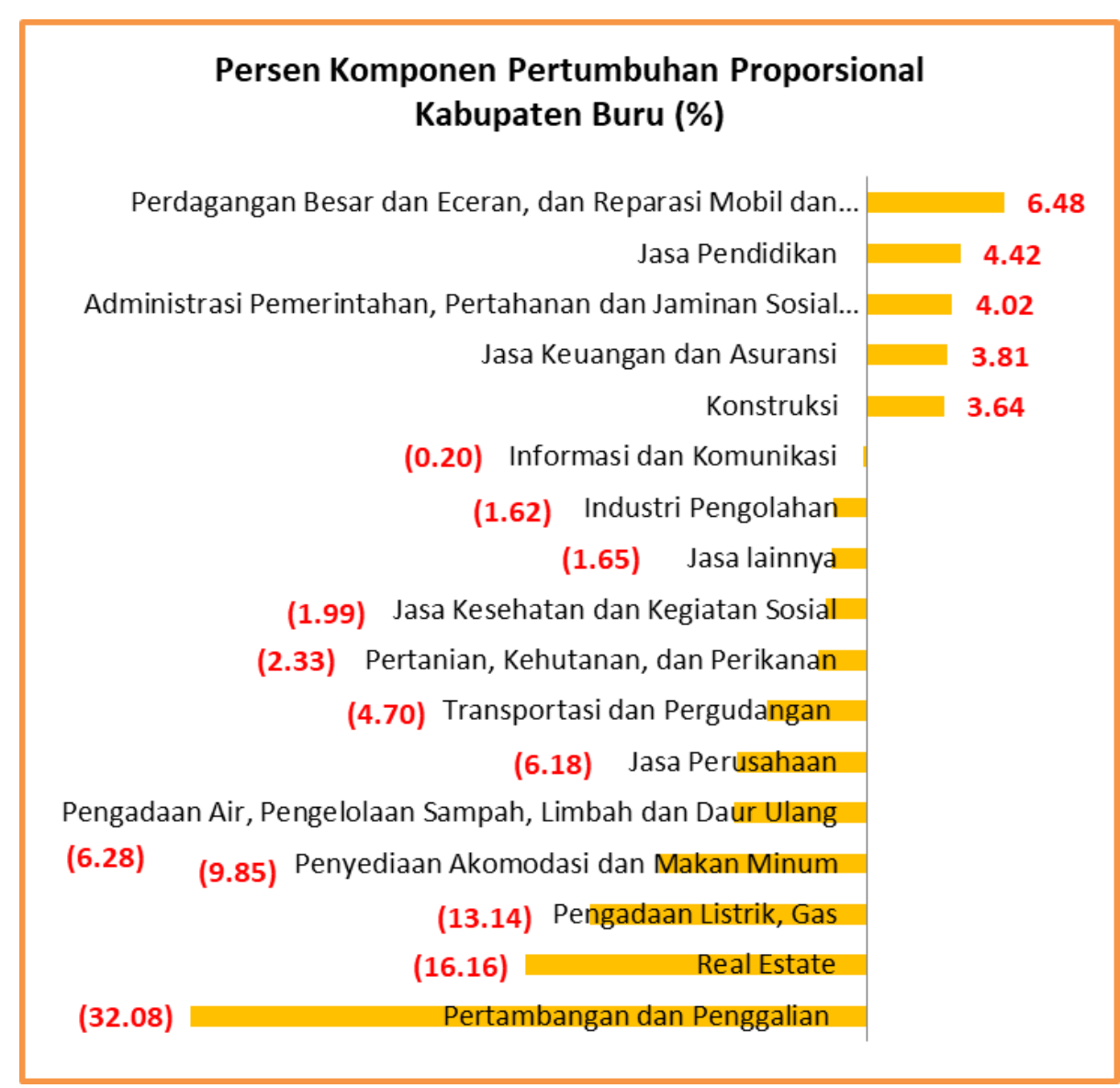

Gambar 4. Komponen Pertumbuhan Proporsional Sektoral di Kabupaten Buru Tahun 2015-2019 (BPS, 2015)

Dari table ini dapat dilihat bahwa Komponen Pertumbuhan Proporsional sangat dipengaruhi oleh berbagai bentuk kebijakan pemerintah dalam membangun daerah. Sehingga factor tersebut harus menjadi fokus perhatian yang tidak bisa disepelekan.

\section{Penutup}

Berdasarkan hasil analisis diketahui bahwa di daerah Kabupaten Buru terdapat lima sektor unggulan yang menjadi basis ekonomi daerah dan terdapat tiga belas sektor lain yang termasuk kedalam sektor non basis. Lima Sektor Unggulan di Kabupaten Buru yang menjadi basis ekonomi daerah antara lain 
Sektor Industri Pengolahan, Sektor Jasa Kesehatan dan Kegiatan Sosial, sektor pertanian, kehutanan dan perikanan, sektor transportasi dan pergudangan dan sektor Real Estate. Sedangkan tiga belas sektor lainnya termasuk kedalam sektor non basis adalah terutama pada sektor yang beriorientasi pada jasa. Selanjutnya besaran nilai multiplier berkorelasi erat dengan aktivitas ekonomi masyarakat. Dan baik sektor basis maupun sektor non basis mengalami pengaruh peningkatan atau penurunan yang berkaitan erat dengan kenaikan atau penurunan pendapatan masyarakat.

\section{Daftar Pustaka}

Armelly, A., Rusdi, M., \& Pasaribu, E. (2021). Analisis sektor unggulan perekonomian Indonesia: Model input-output. Sorot, 16(2), 119. https://doi.org/10.31258/sorot.16.2.119-134

BPS. (2015). PDRB Menurut Lapangan Pengeluaran Kabupaten/Kota di Provinsi Maluku 2010-2014.

Herman Syahputra, A. (2015). Analisis Sektor Unggulan Dan Perubahan Struktur Perekonomian Kabupaten Aceh Barat. Jurnal IImu Ekonomi, 3(3), 56-68.

https://burukab.bps.go.id/. (2019). BPS KABUAPATEN BURU. Https://Burukab.Bps.Go.Id/. https://burukab.bps.go.id/

Lismuba Indriani dan Mohammad Abdul Mukhyi. (2013). SEKTOR UNGGULAN PEREKONOMIAN INDONESIA: PENDEKATAN INPUT-OUTPUT. 5, 8-9.

Ma'ruf, Ahmad. (2003). Penentuan Sektor Unggulan di Provinsi Daerah Istimewa Yogyakarta. Jurnal Ekonomi \& Studi Pembangunan, 4(1).

Mangilaleng, E. J., Rotinsulu, D., \& Rompas, W. (2015). Analisis Sektor Unggulan Kabupaten Minahasa Selatan. Jurnal Berkala Ilmiah Efisiensi, 15(04), 193205.

Marasabessy, R. N., Rumkel, L., Susiati, S., Masniati, A., Tuasalamony, K., Amir, N. F., lye, R., \& Hatuwe, R. S. M. (2021). Analisis potensi dan strategi pariwisata pantai di Kabupaten Buru. Sang Pencerah: Jurnal Ilmiah Universitas Muhammadiyah Buton, 7(1), 149-164. https://doi.org/10.35326/pencerah.v7i1.858

Sam, Belinda, E. a. (2019). Female Feminism in the Customary Island of Buru..." Int. J. Sci. Technol., 8(8), 234-244.

Soeyatno, R. F. (2019). Analasis Penentuan Sektor Unggulan Terhadap Perekonomian Wilayah Kota Bogor Provinsi Jawa Barat Tahun 2012-2016. JURNAL SeMaRaK, 1(3). https://doi.org/10.32493/smk.v1i3.2258

Sugiyono. (2011). Metode Penelitian Kombinasi (Mix Methods). Alfabeta.

Sundaro, H. (2021). Studi Identifikasi Sektor-Sektor Unggulan Kabupaten Semarang. Jurnal Ekonomi, Manajemen Akuntansi Dan Perpajakan (Jemap), 4(1), 1. https://doi.org/10.24167/jemap.v4i1.3126

Tri Basuki, A., \& Gayatri, D. U. (2009). PENENTU SEKTOR UNGGULAN DALAM PEMBANGUNAN DAERAH: Studi Kasus di Kabupaten Ogan Komering llir. Jurnal Ekonomi Dan Studi Pembangunan, 10(1), 34-50. 